\title{
Functionalization and Characterization of MWCNT Produced by Different Methods
}

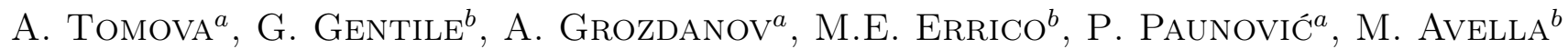 \\ AND A.T. Dimitrov ${ }^{a}$ \\ ${ }^{a}$ Faculty of Technology and Metallurgy, Sts. Cyril and Methodius, Skopje, Macedonia \\ ${ }^{b}$ Institute for Polymers, Composites and Biomaterials, National Research Council, \\ Via Campi Flegrei, 34, 80078 Pozzuoli, Napoli, Italy
}

(Received August 10, 2015; in final form February 2, 2016)

\begin{abstract}
The subject of this study is chemical functionalization as means of structural modification of multiwalled carbon nanotubes. The main goal of the experiments was to create highest density of carboxyl groups on multiwalled carbon nanotubes surface, necessary for further nanocomposite application. Two different types of multiwalled carbon nanotubes (I: outer diameter $d=50 \div 100 \mathrm{~nm}$, purity $\approx 84 \%$, synthesized by pyrolysis and II: outer diameter $d=10 \div 40 \mathrm{~nm}$, purity $\approx 94 \%$, synthesized by chemical vapor deposition) were treated by concentrated nitric acid $\left(\mathrm{HNO}_{3}\right)$ and by alkaline mixture $\left(\mathrm{NH}_{4} \mathrm{OH}+\mathrm{H}_{2} \mathrm{O}_{2}\right)$. The alkaline medium as "milder" and less aggressive than nitric acid, was expected to be less destructive and cause minimal structural damage on multiwalled carbon nanotubes surface. Structural changes due to oxidation were observed by the Raman analysis, while the ratio of the intensities of the $D$ and $G$ peak was used to estimate the concentration of defects. Pristine and functionalized multiwalled carbon nanotubes were characterized by thermogravimetric analysis, scanning electron microscopy, ultraviolet-visible spectroscopy and zeta $(\zeta)$ spectroscopy. The results showed that functionalization initiates changes in carbon nanotubes structure as well as in their density of states. It also results in carbon nanotubes shortening and exfoliation and decreases their agglomeration tendency. Carbon nanotubes functionalized by both acid and alkaline treatment can successfully replace conventional carbon fibers as fillers in polymer composites for sensing application.
\end{abstract}

DOI: 10.12693/APhysPolA.129.405

PACS/topics: 81.07.De

\section{Introduction}

Since their discovery in $1991[1,2]$ carbon nanotubes (CNT) have received an enormous attention as a new class of materials. Due to their inherent and extraordinary physical, chemical, electronic [3, 4], and mechanical properties [5], CNTs have raised much interest and provided exciting opportunities for producing advanced materials for new applications [6-9]. They have fast become one of the most researched topics and interest in different scientific fields such as batteries, hydrogen storage, gas sensors [10], optoelectronic devices [11], and catalysts [12].

The potential of CNTs as reinforcing elements in composites is also based on their relatively high aspect ratio $(L / d)$ and surface area to volume ratio $(A / V)$ [13-15].

However, CNTs are severely entangled and homogeneous dispersion of CNTs is relatively difficult to achieve. Their extremely low solubility in any solvent [16] and difficult dispersion is considered as a significant barrier both for research and industrial application. Carbon nanutubes have the tendency to form long bundles that are thermodynamically stabilized by strong $\pi-\pi$ interactions [17] and van der Waals binding energy about $500 \mathrm{eV} \mu \mathrm{m}^{-1}$ of tube-tube contact [18]. As modification means for breaking down the strong $\pi-\pi$ interactions, thus improving dispersion many techniques have been used so far. They include ultrasonication, addition of surfactant [19] and chemical functionalization of the
CNTs surface [20]. Various anionic, cationic and nonionic surfactants which adsorb on the CNTs surface, can effectively minimize the strong attraction between CNTs by ways of electrostatic repulsion or steric hindrance [21-25]. Surface functionalization of CNTs is essential and has a significant role in improving the solubility and dispersion of CNTs in aqueous solutions. Surface modification imparts various functional groups, such as hydroxyl, carboxyl, amine and vynil, and their adsorption onto CNTs surface is responsible for the various physicochemical and catalytic properties of the modified material. These oxygen containing functional groups can be introduced by mechanical [26], chemical [27] and electrochemical techniques [28]. The amount and type of attached functional groups strongly depends on the type of surface modification applied. Though introducing sufficient amount of oxygen containing functional groups thus improving dispersion of CNTs, chemical modification often leads to significant defects on CNTs surface and cutting [29-38].

In this paper, chemical functionalization of multiwall carbon nanotubes (MWCNTs) films was studied as a well established and efficient method for surface modification of CNTs. Thermal stability, surface and chemical composition, as well as presence of functional groups on CNTs surface caused by oxidation, are investigated by thermogravimetry (TGA/DTA), Raman spectroscopy, scanning electron microscopy (SEM) and energy dispersive spectroscopy (EDX), infrared spectroscopy (FTIR), 
UV spectroscopy and zeta potential. The studied CNTs were further employed as fillers in various polymers for gas sensing [39].

\section{Experimental}

In the conducted experiments presented in this work, two types of MWCNTs were used: MWCNTs synthesized by pyrolysis (type A: $d=50 \div 100 \mathrm{~nm}$, purity $\approx 84 \%$ ) (produced in our laboratory) and MWCNTs (commercial) obtained by CVD technique (type $\mathrm{P}: d=10 \div 40 \mathrm{~nm}$, purity $\approx 94 \%$ ) and commercialized by CNTCO Ltd. MWCNTs were further purified/activated by two different methods: (i) wet acid $\left(\mathrm{HNO}_{3}\right.$, samples A2 and P2) and (ii) wet base oxidation $\left(\mathrm{NH}_{4} \mathrm{OH}+\mathrm{H}_{2} \mathrm{O}_{2}\right.$, samples $\mathrm{A} 3$ and P3). MWCNTs purity was estimated by EDS (for MWCNTs obtained by pyrolysis) and manufacturer's specification (for MWCNTs obtained by CVD). In particular, CNTs were activated in a flask, with $28 \% \mathrm{HNO}_{3}$ and $\mathrm{NH}_{4} \mathrm{OH}+\mathrm{H}_{2} \mathrm{O}_{2}$, respectively. The mixtures were magnetically stirred at $900 \mathrm{rpm}$, at room temperature over a period of $3 \mathrm{~h}$. Then they were vacuum filtered and dried under vacuum at $95^{\circ} \mathrm{C}$ for $12 \mathrm{~h}$.

Modified MWCNTs were subject to characterization by means of the Raman analysis, TGA, SEM, ultravioletvisible spectroscopy (UV-Vis) and zeta $(\zeta)$ spectroscopy.

TGA was performed in the range of 50 to $800^{\circ} \mathrm{C}$ with heating rate of $20 \mathrm{~K} / \mathrm{min}$ (in $\mathrm{N}_{2}$ ) using a Perkin Elmer Pyris DIAMOND TGA/DTA system. SEM photos were recorded with a FEI Quanta 200 scanning electron microscope using an acceleration voltage of $30 \mathrm{kV}$ with EDS Oxford Inca Energy 350, equipped with secondary electron detector. The Raman spectra were collected using a $785 \mathrm{~nm}$ (Titan sapphire laser), Jobin-Yvon HR640 spectrometer fitted with an Andor Technology CCD detector. UV spectra were recorded with Varian Scan $50 \mathrm{UV}$ Spectrophotometer with $1 \mathrm{~cm}$ quartz cell at $25^{\circ} \mathrm{C}$. Zeta potential measurements were carried out by measuring the surface potential of CNTs for evaluating their colloidal stability. Zeta potential values were obtained by Zeta Meter System 4.0.

\section{Results and discussion}

The effects of purification and functionalization of MWCNTs were analyzed by the Raman spectroscopy, UV and zeta spectroscopy. Characteristic Raman spectra are shown in Fig. 1 and Fig. 2, while the corresponding $I_{\mathrm{D}} / I_{\mathrm{G}}$ ratio is the following: sample $\mathrm{A} 1-1.2, \mathrm{~A} 2-1.1$, $\mathrm{A} 3-0.9, \mathrm{P} 1-1.3, \mathrm{P} 2-0.89, \mathrm{P} 3-1.25$.

The Raman spectra and $I_{\mathrm{D}} / I_{\mathrm{G}}$ ratio for the two types of MWCNTs show changes in CNTs structure after both acid and base treatment. In the case of A-type MWCNTs base treatment proves to decrease the disorder in structure and there is no generation of new amorphous carbon, while P-type CNTs show a negligible effect with respect to pristine nanotubes. This can result from the differences in the type of CNTs i.e. method of synthesis and purity. The results are in correlation to

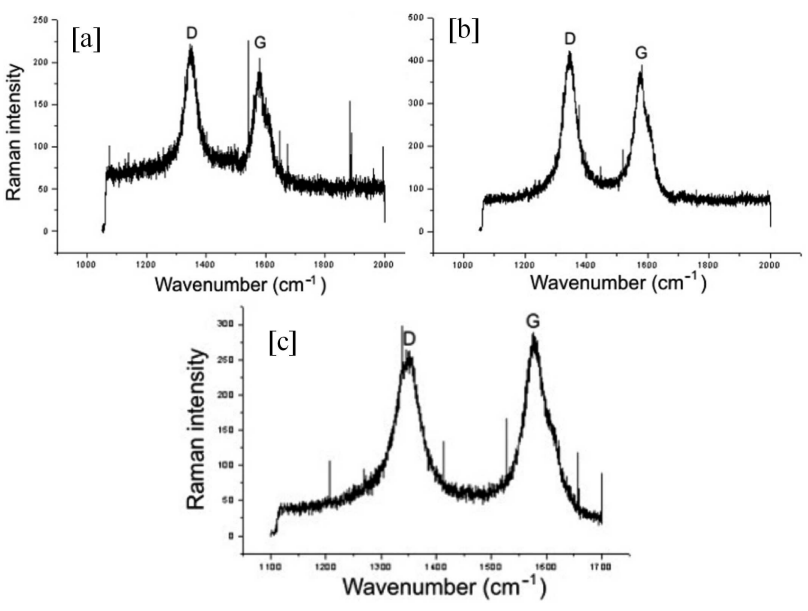

Fig. 1. Raman spectra of MWCNTs A-type: (a) pristine, (b) acid treatment, (c) base treatment.

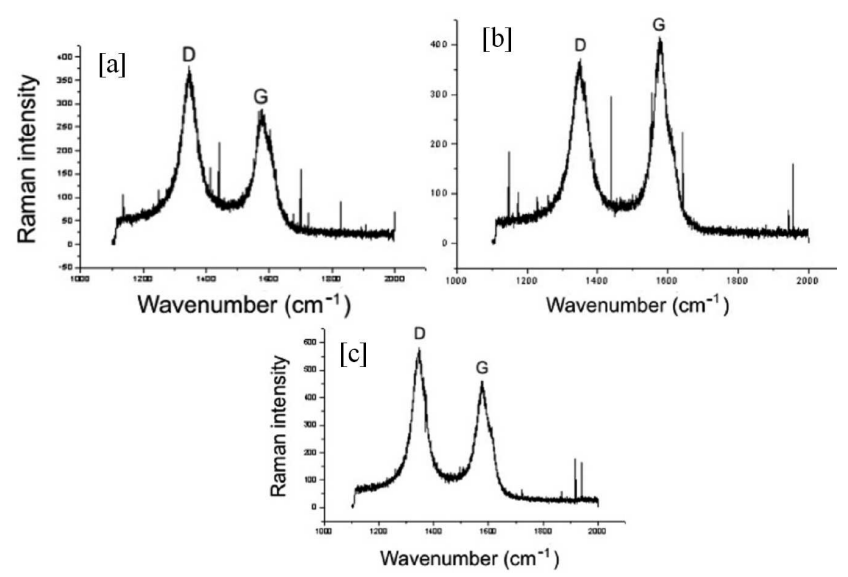

Fig. 2. Raman spectra of MWCNTs P-type: (a) pristine, (b) acid treatment, (c) base treatment.

Datsyuk et al. [40] that have investigated CVD produced MWCNTs purified with $\mathrm{HCl}, \mathrm{HNO}_{3}, \mathrm{H}_{2} \mathrm{SO}_{4}$ and $\mathrm{NH}_{4} \mathrm{OH}+\mathrm{H}_{2} \mathrm{O}_{2}$.

Figure 3 shows SEM microphotographs of pristine/functionalized MWCNTs. It can be noted that all samples show presence of smaller aggregates and tangled clusters. After functionalization (especially treatment with nitric acid) CNTs have been slightly shortened.

The quality of pristine and purified/modified MWCNTs was examined by UV-Vis spectroscopy. Obtained UV spectra are shown in Fig. 4.

UV-Vis spectra of A-type MWCNTs show intensive absorption peak at 200-230 nm, while P-type MWCNTs show this peak at $250 \mathrm{~nm}$. It is evident that absorption peaks for pristine and purified P-type CNTs appear in the range of longer wavelengths in the spectra and are wider than those of the A-type samples. These absorption peaks are attributed to changes in density of states (DOS) in the electronic structure of CNTs.

UV spectra of A-type MWCNTs samples show absence of Van Hove shifts (series of sharp peaks in the spectra) in $400-800 \mathrm{~nm}$ range of wavelengths. This is probably due 


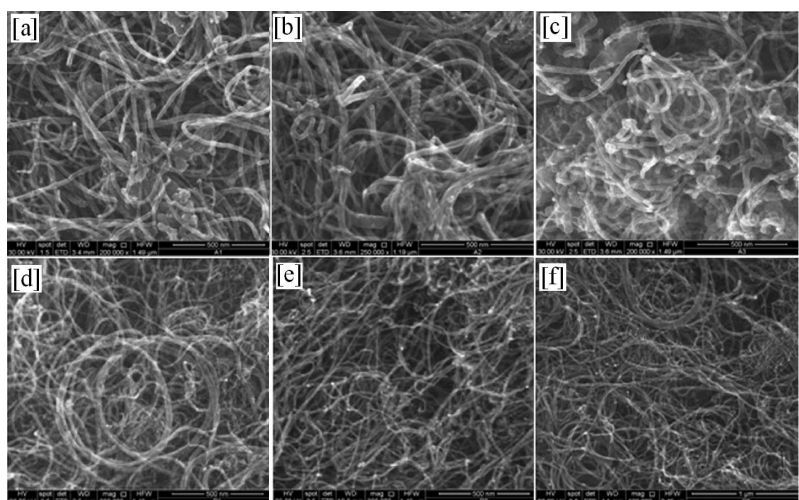

Fig. 3. SEM of MWCNTs: (a) pristine A-type MWCNTs, (b) A-type f-MWCNTs $\left(\mathrm{HNO}_{3}\right)$, (c) A-type fMWCNTs $\left(\mathrm{NH}_{4} \mathrm{OH}+\mathrm{H}_{2} \mathrm{O}_{2}\right)$, (d) pristine P-type MWCNTs, (e) P-type f-MWCNTs $\left(\mathrm{HNO}_{3}\right)$, (f) P-type fMWCNTs $\left(\mathrm{NH}_{4} \mathrm{OH}+\mathrm{H}_{2} \mathrm{O}_{2}\right)$.

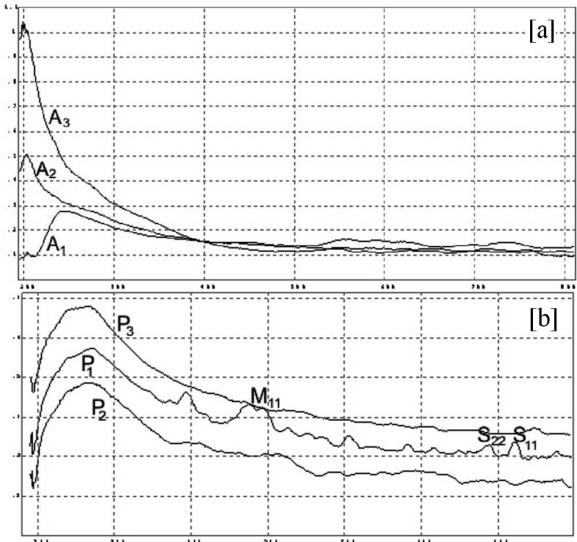

Fig. 4. UV spectra of MWCNTs: (a) A-type, (b) Ptype.

to lower DOS, which in turn result in weaker absorption of light in the range of longer wavelengths [41].

Pristine P1 sample shows two peaks in the range of $750-900 \mathrm{~nm}$. Namely, the first peak at $775 \mathrm{~nm}$ is attributed to $S_{22}$ Van Hove shift, while the second one at $825 \mathrm{~nm}$ to energetically lower $S_{11}$ Van Hove shift. From the UV spectra it is evident that after functionalization (P2 and P3 samples) $S_{22}$ vanishes, while $S_{11}$ decreases intensity. This shows that after wet acid and base treatment, change in the electronic structure of CNTs is achieved. According to certain studies [42, 43], covalent functionalization of MWCNTs can lead to disruption in the aromatic system, which in turn can result in electroconductivity changes. UV spectra registers these as changes in the intensity of Van Hove shifts.

For most real systems, one cannot measure the surface potential. However, one can measure the electrostatic mobility of the particles and calculate zeta potential $(\zeta)$. As an ionic surfactant, sodium dodecyl sulfate (SDS) was used. Colloids with $\zeta$ higher than $25 \mathrm{mV}$ (negative or positive) are electrically stabilized, while colloids with lower magnitudes of $\zeta$ tend to coagulate or flocculate [44].
Magnitudes of zeta potential $(\zeta)$ of the examined CNTs are the following: sample SW2 - 43.20, MW3 - 34.60, $\mathrm{A} 1-48.50, \mathrm{~A} 2-39.14, \mathrm{~A} 3-31.57, \mathrm{P} 1-33.80$, $\mathrm{P} 2-33.23, \mathrm{P} 3-35.00$ (at temperature of $15^{\circ} \mathrm{C}$ and applied voltage $100 \mathrm{~V}$ ) and it can be concluded that all samples have positive zeta potential, which can be result of insufficiently adsorbed oxygen functional groups after the modification and $\mathrm{pH}$ of the suspension [45].

The results indicate that for both pristine and purified CNTs high magnitudes for $\zeta$ were obtained, i.e. they show colloidal stability. Comparison of magnitudes shows that acid treatment provides higher zeta potential for A-type CNTs, while wet alkaline treatment for P-type CNTs.

Themogravimetric analysis was used to study the thermal stability of pristine and modified MWCNTs. Characteristic TGA/DTA thermograms are shown in Fig. 5.

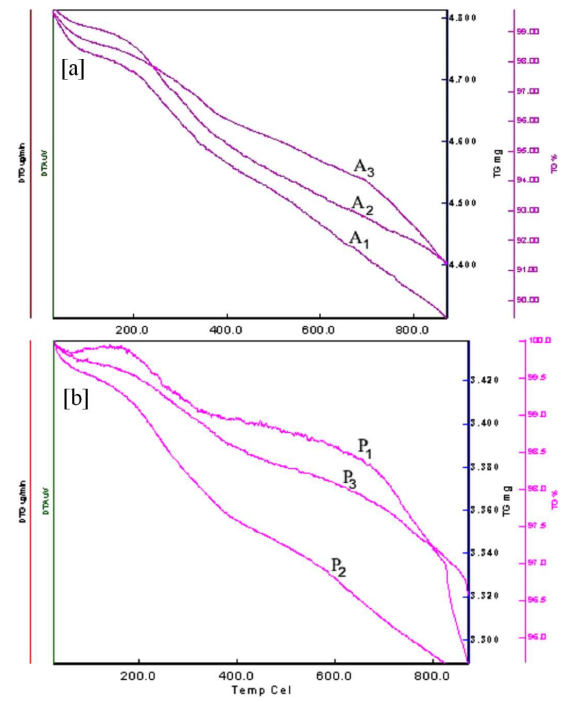

Fig. 5. TGA thermograms of pristine and thermally oxidized MWCNTs: (a) A-type, (b) P-type.

TGA curves have shown that during the heating of the MWCNTs in the range of $25-800^{\circ} \mathrm{C}$, rapid mass loss combined with the energy effects in $200-400{ }^{\circ} \mathrm{C}$ (water and $\mathrm{CO}_{2}$ removal $)$ and $600-800^{\circ} \mathrm{C}\left(\mathrm{CO}_{2}\right.$ and $\mathrm{CO}$ removal $)$ occurred. The weight loss at $600-800^{\circ} \mathrm{C}$ could be assigned to decomposition of $-\mathrm{COOH}$ groups [46].

\section{Conclusions}

Characterization of oxidized CNTs shows changes in CNTs structure as a result of functionalization. The disorder in crystallinity is confirmed by the Raman spectroscopy and the decrease in $I_{\mathrm{D}} / I_{\mathrm{G}}$ ratio of treated vs. pristine CNTs. The Raman spectra of functionalized CNTs also register change in $I_{\mathrm{D}} / I_{\mathrm{G}}$ ratio in all samples, but more dramatic effect is achieved in MWCNTs obtained by pyrolysis. UV spectroscopy reveals shifts of the Van Hove peaks towards lower wavelengths. SEM shows presence of smaller aggregates and tangled clusters. After functionalization (especially treatment with nitric acid) CNTs have been slightly shortened. Functionalization 
of CNTs facilitates shortening and exfoliation of CNTs and decreases their agglomeration tendency. The magnitude of zeta potential of the observed samples ranges between 31 and $48.5 \mathrm{mV}$, which implies colloidal stability. Acid treatment provided higher zeta potential for A-type CNTs, while alkaline treatment for $p$-type CNTs.

\section{References}

[1] S. Iijima, Nature 354, (1991).

[2] A. Merkoci, M. Pumera, X. Llopis, B. Perez, M. Del Valle, S. Alegret, TRAC Trends Anal. Chem. 24, 9 (2005).

[3] P.M. Ajayan, Chem. Rev. 99, 7 (1999).

[4] E. Katz, I. Willner, Chem. Phys. Chem. 5, 8 (2004).

[5] S. Orlanducci, V. Sessa, M.L. Terranova, G.A. Battison, S. Battison, R. Gergasi, Carbon 44, 13 (2006).

[6] R. Hu, B.A. Cola, N. Haram, I.N. Barisci, S. Lee, S. Stoughton, G. Wallace, C. Too, M. Thomas, A. Gestos, M.E. de la Cruz, J.P. Ferraris, A.A. Zakhidov, R.H. Baughman, Nano Lett. 10, 3 (2010).

[7] M.S. Arnold, J.D. Zimmerman, C.K. Renshaw, X. Xu, R.R. Lunt, C.M. Austin, S.R. Forrest, Nano Lett. 9, 9 (2009).

[8] K.P. Yung, J. Wei, B.K. Tay, Diamond Relat. Mater. 18, 9 (2009).

[9] Y.C. Tsai, J.D. Huang, C.C. Chiu, Biosens. Bioelectron. 22, 12 (2007).

[10] S. Ciraci, S. Dag, T. Yildrim, O. Gulseren, R.T. Senger, J. Phys. Condens. Matter 16, 29 (2004).

[11] Q.H. Wang, M. Yan, R.P.H. Chang, Appl. Phys. Lett. 78, 1294 (2001).

[12] N. Karousis, G.E. Tsotsou, F. Evangelista, P. Rudolf, N. Ragoussis, N. Tagmatarchis, J. Phys. Chem. C 112, 35 (2008).

[13] E.T. Thostenson, Z. Ren, T.W. Chou, Compos. Sci. Technol. 61, 13 (2001).

[14] E.T. Thostenson, C. Li, T.W. Chou, Compos. Sci. Technol. 65, 2005 (2005).

[15] S.C. Tjong, Express Polym. Lett. 4, 9 (2010).

[16] N. Nakashima, Int. J. Nanosci. 4, 1 (2005).

[17] D. Tasis, N. Tagmatarchis, A. Bianco, M. Prato, Chem. Rev. 106, 3 (2006).

[18] A. Thess, R. Lee, P. Nikolaev, Science 273, 5274 (1996).

[19] J. Liu, A.G. Rinzler, H. Dai, J.H. Hafner, R.K. Bradley, P.J. Boul, A. Lu, T. Iverson, K. Shelimov, C.B. Huffman, Science 280, 5367 (1998).

[20] H. Zhang, H.X. Li, H.M. Cheng, J. Phys. Chem. B 110, 18 (2006)

[21] O. Matarredona, H. Rhoads, Z. Li, J.H. Harwell, L. Balza, D.E. Resasco, J. Phys. Chem. B 107, 48 (2003).

[22] K. Yurekli, C.A. Mitchell, R. Krishnamoorti, J. Am. Chem. Soc. 126, 32 (2004).

[23] N. Grossiord, O. Regov, J. Loos, J. Meuldijk, C.E. Koning, Anal. Chem. A 77, 16 (2005).

[24] D. Li, H. Wang, J. Zhu, X. Wang, L. Lu, X. Yang, J. Mater. Sci. Lett. 22, 4 (2003).
[25] Z.H. Wang, G.A. Luo, S.F. Xiao, Proc. IEEE Sensors 2, (2003).

[26] J.P. Boudou, J.I. Paredes, A. Cuesta, A. MartinezAlonso, J.M.D. Tascon, Carbon 41, 41 (2003).

[27] F. Xie, J. Phillips, J.F. Silva, M.C. Palma, J.A. Menendez, Carbon 38, 5 (2000).

[28] C.C. Hu, C.C. Wang, J. Power Source 125, 2 (2004).

[29] M.S.P. Shaffer, A.H. Windle, Adv. Mater. 11, 11 (1999).

[30] X.L. Xie, Y.W. Mai, X.P. Zhou, Mater. Sci. Eng. R Rep. R49, 4 (2005).

[31] M.S.P. Shaffer, X. Fan, A.H. Windle, Carbon 36, 11 (1998).

[32] J. Chen, A.M. Rao, S. Lyuksyutov, M.E. Itkis, M.A. Hamon, H. Hu, R.W. Cohn, P.C. Eklund, D.T. Colbert, R.E. Smalley, R.C. Haddon, J. Phys. Chem. B 105, 13 (2001).

[33] J. Liu, A.G. Rinzler, H. Dai, J.H. Hafner, R.K. Bradley, P.J. Boul, A. Lu, T. Iverson, K. Selimov, C.B. Huffman, F. Rodriguez-Macias, Y.S. Shon, T.R. Lee, D.T. Colbert, R.E. Smalley, Science 280, 5367 (1998).

[34] C. Gao, Y.Z. Jin, H. Kong, R.L.D. Whitby, S.F.A. Acquah, G.Y. Chen, H. Qian, A. Hartschuh, S.R.P. Silva, S. Henley, P. Fearon, H.W. Kroto, D.R.M. Walton, J. Phys. Chem. B 109, 24 (2005).

[35] K. Kamaras, M.E. Itkis, H. Hu, B. Zhao, R.C. Haddon, Science 301, 5639 (2003).

[36] J. Chen, M.A. Hamon, H. Hu, Y. Chen, A.M. Rao, P.C. Eklund, R.C. Haddon, Science 282, 5386 (1998).

[37] V. Georgakilas, N. Tagmatarchis, D. Pantarotto, A. Bianco, J.P. Briand, M. Prato, Chem. Commun. 2002, (2002).

[38] D. Tasis, N. Tagmatarchis, V. Georgakilas, M. Prato, Chemistry 9, 17 (2003).

[39] A. Tomova, A. Petrovski, A. Grozdanov, B. Andonović, P. Paunović, A.T. Dimitrov, in: $M M$ SEE 2015 - Metalurgical and Materials Engineering Congress on South-East Europe, Belgrade, Marija Korać, Association of Metallurgical Engineers of Serbia, Belgrade 2015, p. 336.

[40] V. Datsyuk, M. Kalyva, K. Papagelis, J. Parthenios, D. Tasis, A. Siokou, I. Kallitsis, C. Galiotis, Carbon 46, 6 (2008).

[41] J. Guo, C. Yang, Z.M. Li, M. Bai, H.J. Liu, Phys. Rev. Lett. 93, 1 (2004).

[42] J.L. Bahr, J. Yang, D.V. Kosynkin, M.J. Bornikowski, R. Smalley, J.M. Tour, J. Am. Chem. Soc. 123, 27 (2001).

[43] V.A. Sinani, M.K. Gheit, A.A. Yaroslav, A.A. Rakhnyanskaya, K. Sun, A.A. Mamedov, J.P. Wicksted, N.A. Kotov, J. Am. Chem. Soc. 127, 10 (2005).

[44] X.Qin X, J. Liu, Â F. Wang, Â Jing Ji,ÂA. Electroanal. Chem. 651, 2 (2011).

[45] Y. Liu, L.A. Gao, Carbon 43, 1 (2005).

[46] G. Trykowski, S. Biniak, L. Stobinski, B. Lesiak, Acta Phys. Pol. A 118, 515 (2010). 